TP Periodica Polytechnica Civil Engineering

61(3), pp. 530-540, 2017

https://doi.org/ 10.3311/PPci.9621

Creative Commons Attribution (1)

RESEARCH ARTICLE

\section{An Experimental Study on Relationship among Water Sorptivity, Pore Characteristics, and Salt Concentration in Concrete}

\author{
Hailong Ye $\mathrm{Y}^{1,2, *}$, Nanguo Jin ${ }^{1}$, Xianyu Jin ${ }^{1}$
}

Received 17 June 2016; Revised 14 September 2016; Accepted 12 December 2016

\begin{abstract}
In this work, the sorptivity properties of concrete with various types of supplementary cementitious materials (SCMs) cured at three different curing regimes was investigated using the gravimetric method. In parallel, the effects of four different concentrations of sodium chloride solution on the sorptivity of concrete were studied using both gravimetric and electronic methods. The results show that the incorporation of SCMs reduces the sorptivity of concrete when sufficient moisture curing is provided; otherwise, it exacerbates sorptivity. Nevertheless, there exists a strong correlation between the sorptivity coefficient and threshold pore size of concrete measured by mercury intrusion porosimetry. The gravimetric and electronic methods show different trends regarding the effects of liquid properties on sorptivity, probably because the gravimetric method cannot differentiate the weight of water from salts during the measurements.
\end{abstract}

\section{Keywords}

concrete, concrete cover, sorptivity coefficients, curing condition, mineral admixtures

${ }^{1}$ College of Civil Engineering and Architecture, Zhejiang University, Hangzhou 310058, P.R. China

${ }^{2}$ Department of Civil and Environmental Engineering, The Pennsylvania State University, 3127 Research Drive, State College, PA, 16801, United States *Corresponding author, email: yehailong1@gmail.com

\section{Introduction}

Chloride-induced steel corrosion has been a major deteriorating mechanism for reinforced concrete structures exposed to marine environments [1,2]. The initiation of corrosion originates from a high chloride concentration in pore solution which depassivates the protecting film around rebars [3]. In order to accurately predict the time from construction to corrosion initiation, it is essentially important to characterize the chloride ingress process in concrete cover [4-6]. However, depending on the exposure condition, the members of marine structures are typically exposed to four different types of chloride-bearing environments: submerged zone, tidal zone, splash zone, and atmospheric zone. Among these, tidal and splash zones were recognized to be the most unfavorable condition for marine structure since it accelerates the chloride ingress and corrosion [7-10].

In tidal/splash zone, the surface of concrete is subjected to a cyclic drying-wetting action, which accumulates the chloride ions easier than other conditions. During drying period, the evaporation of water condenses the chloride concentration in the pore solution, probably accompanied by the precipitation of chloride-bearing phases. Upon re-wetting, the aggressive salts from seawater are transported by a mean of capillary absorption for unsaturated concrete. The rate of capillary absorption is critically important for concrete since it is indirectly related to the ingress rate of chloride ions. As such, capillary absorption properties has been widely used as an important factor for quantifying the durability of cement and concrete materials [11].

Capillary absorption describes the Darcian flow through an unsaturated porous media in response to the capillary forces [12]. Theoretically, the rate is capillary absorption (also commonly known as sorptivity coefficient) is affected by the pore structure of materials (e.g. volume of water-accessible pores, connectivity, and tortuosity), and properties of the liquid (e.g. surface tension, viscosity, density, hydrophilicity). Practically, the sorptivity properties of concrete was reported to be affected by the initial moisture content [13], curing condition [14, 15], incorporation of supplementary cementitious materials (SCMs) $[15,16]$, type of cement and aggregate [12], volumetric fraction of paste (or aggregate) [14, 17], water-to-binder ratio [17], 
temperature [13], and presence of salts in solution [13]. For example, Castro et al. reported that the water absorption test is considerably affected by the relative humidity $(\mathrm{RH})$ of the samples before starting the test, which if not properly accounted for can lead to a misunderstanding of the actual absorption behavior [14]. Liu et al found that the sorptivity increases as the replacement ratio of fly ash increases for moisture-cured concrete [18]. However, Gopalan reported that for concrete with fly ash incorporation, its capillary absorption is more sensitive to the curing condition, compared with ordinary Portland cement concrete. A recent study on the capillary sorption test for concrete with blast-furnace slag showed a similar performance, indicating that the concrete with SCMs shows a strong dependence on curing condition [15]. Some researchers attempted to reveal the correlation between sorptivity, pore volume, and threshold diameter for concrete with SCMs. For example, Khtib reported a positive correlation between the absorption of concrete and the intruded pore volume of paste for concrete with/without slag [15]. Liu et al found that a higher porosity and lower tortuosity lead to higher surface sorptivity for concrete with fly ash [18]. However, little attempt was made by previous researchers to investigate the reason why the incorporation of SCMs makes the sorptivity of concrete more sensitive to the curing condition.

On the other hand, there exist disputes regarding the influence of chloride concentration on capillary absorption properties of concrete. For instance, Macinnis et al found that the sorptivity of 2, 4 and $10 \%$ sodium chloride $(\mathrm{NaCl})$ solutions are similar to that of water by using traditional gravimetric method [19]. However, by observing the chloride profiles in concrete, McCarter et al. fond that chloride front moves at a slightly lower rate than that of water in concrete [12]. In addition, Liu et al. found that the immersion in $\mathrm{NaCl}$ solution reduces the long-term sorptivity by physically blocking the pore network as the formation of Friedel's salts [18]. It seems that the gravimetric method has limitations in differentiating the influence of liquid properties on sorptivity of concrete. There is, however, few study on implementing an electronic method to quantify the sorptivity behaviors of concrete with various liquid properties. Considering that the electronic response of concrete is strongly associated with the moisture content [20], monitoring the depth-related variation in electronic response would provide new insights on sorptivity of concrete.

The objective of this study is comprised of two parts: one is to characterize the sensitivity of capillary sorption tests of concrete with SCMs in response to various curing conditions. It aims to better understand the correlation between sorptivity and pore structure parameters of concrete. The second part is to characterize the influence of chloride concentration on the short-term sorptivity of concrete using both gravimetric and electronic methods, and the results obtained by these two methods were compared.

\section{Experimental Program \\ 2.1 Materials}

The ordinary Portland cement (OPC) with a grade of P.O. 52.5 (according to Chinese Standard GB175-2007, equivalent to ASTM Type I cement) and mineral composition as listed in Table 1, was used in this study. The alkali content (denoted as $\mathrm{Na}_{2} \mathrm{O}+0.658 \mathrm{~K}_{2} \mathrm{O}$ ) is less than $0.60 \%$, and the fineness is 350 $\mathrm{m}^{2} / \mathrm{kg}$. Grade S95 (according to Chinese Standard GB/T180462000) ground granulated blast-furnace slag with the fineness of $450 \mathrm{~m}^{2} / \mathrm{kg}$, and Grade I Class F fly ash (according to Chinese Standard GB/T1596-2005) with the fineness of $400 \mathrm{~m}^{2} /$ $\mathrm{kg}$, were used as SCMs. The chemical composition of blastfurnace slag and Class F fly ash are listed in Table 2. The fine aggregate was river sand with a fineness modulus of 2.64. The coarse aggregate was crushed gravel with a maximum size of $20 \mathrm{~mm}$ and continuous grading ranges from $5 \mathrm{~mm}$ to $20 \mathrm{~mm}$. The water was from tape water.

Table 1 Mineral composition of ordinary Portland cement (mass \%)

\begin{tabular}{cccccc}
\hline $\begin{array}{c}\text { Mineral } \\
\text { composition }\end{array}$ & $\mathbf{C}_{3} \mathbf{S}$ & $\mathbf{C}_{2} \mathbf{S}$ & $\mathbf{C}_{3} \mathbf{A}$ & $\mathbf{C}_{\mathbf{4}} \mathbf{A F}$ & Gypsum \\
\hline Content & 55.5 & 19.1 & 6.5 & 10.1 & 5 \\
\hline
\end{tabular}

\subsection{Mixing proportion}

This study has two series of mixing proportion, as shown in Table 3, in which Series A involves the concrete with various SCMs, while Series B involves merely OPC mortars. In particular, Series A was implemented to investigate the capillary absorption properties of concrete with SCMs cured at various conditions, while Series B was implemented to investigate the influence of chloride concentration.

\subsection{Sample Preparation}

For Series A, the configuration of samples was cubes with a side length of $100 \mathrm{~mm}$. The samples were demolded after casting for 24 hours, followed by three different types of curing regime:

For curing regime $I$, the samples were soaked in the water at $20{ }^{\circ} \mathrm{C}$, which mimics the environment of submerged harbor structures or partially tidal zone exposed structures.

For curing regime $I I$, the samples were covered by a stack of humidifying sponges at $20^{\circ} \mathrm{C}$, where the RH was measured to be higher than $95 \% \mathrm{RH}$ around the surface of samples. It mimics the curing methods used in some construction sites by covering concrete surfaces with hessian or gunny bags.

For curing regime III, the samples were exposed to a condition in which the temperature is about $40-48{ }^{\circ} \mathrm{C}, \mathrm{RH}$ is about $25 \sim 43 \% \mathrm{RH}$, and air speed at the surface is about $1.67 \sim 1.75 \mathrm{~m} / \mathrm{s}$. It mimics the potential naturally inappropriate curing condition for concrete. 
Table 2 Chemical composition of blast-furnace slag and Class F fly ash

\begin{tabular}{|c|c|c|c|c|c|c|c|c|c|}
\hline Oxidation & $\mathrm{CaO}$ & $\mathrm{SiO}_{2}$ & $\mathrm{Al}_{2} \mathrm{O}_{3}$ & $\mathrm{Fe}_{2} \mathrm{O}_{3}$ & MgO & $\mathrm{SO}_{3}$ & $\mathrm{~K}_{2} \mathrm{O}$ & $\mathrm{Na}_{2} \mathrm{O}$ & LOI \\
\hline Slag & $25 \sim 40$ & $\sim 30$ & $10 \sim 15$ & $1 \sim 2$ & $<6$ & $<6$ & $0.4 \sim 1.5$ & $0.05 \sim 0.5$ & $0.2 \sim 1$ \\
\hline Fly ash & $3 \sim 10$ & $\sim 50$ & $16 \sim 35$ & $3 \sim 22$ & $0.5 \sim 1$ & $0.6 \sim 1$ & $0.4 \sim 1.5$ & $0.05 \sim 0.5$ & $0.8 \sim 3$ \\
\hline
\end{tabular}

Table 3 Mixing proportion of concrete $\left(\mathrm{kg} / \mathrm{m}^{3}\right)$

\begin{tabular}{ccccccccc}
\hline Series ID & Mixture ID & Cement & Fly ash & Slag & Sand & Coarse Aggregate & Water & Water-to-binder ratio \\
\hline & OPC & 368 & 0 & 0 & 735 & 1103 & 195 \\
Series A & BS & 184 & 0 & 184 & 735 & 1103 & 195 \\
& FA & 257 & 110 & 0 & 735 & 103 & 0.53 \\
\hline Series B & MC & 557 & 0 & 0 & 836 & 0.53 & 0.35 \\
\hline
\end{tabular}

After curing at various curing regimes for 7 and 28 days, all samples were saw-cut into two separated slices $(100 \mathrm{~mm} \times 100$ $\mathrm{mm} \times 50 \mathrm{~mm}$ ). The samples were dried in an environmental chamber at $60 \% \mathrm{RH}$ for 7 days, then oven-dried at $70{ }^{\circ} \mathrm{C}$ for 24 hours, followed by an oven-drying at $105^{\circ} \mathrm{C}$ for another 24 hours. Afterwards, the weight of samples was recorded every two hours until the weight almost reached a constant value for three successive measurements (the accuracy of the balance was 0.1 gram). After cooling down to room temperature, five surfaces of each sample were waxed, leaving only the one surface which was newly-exposed by saw-cutting for absorbing the liquid. The weights of all samples were measured before operating the capillary absorption tests.

For Series B, all samples (same size as the samples in Series A) were cured in the moist room $\left(100 \% \mathrm{RH}\right.$ and $\left.20 \pm 5^{\circ} \mathrm{C}\right)$ for $1,3,7,28$ days after demolding. Afterwards, they were dried, wax-treated, weighted using the similar procedures as implemented for Series A.

\subsection{Gravimetric method (ASTM C1585)}

The conventional gravimetric-based capillary absorption tests were conducted for both Series A and Series B, in an environment of $20 \pm 2{ }^{\circ} \mathrm{C}$ and $75 \% \mathrm{RH}$. Dried sillies were placed on supports in a shallow tray and water was added until the water level was about $2.0 \pm 1.0 \mathrm{~mm}$ above the base of the samples in contact with water. The weights of samples were measured at a regular interval after the contact surface was manually wiped with a non-absorbing cloth. The mass of water absorbed per unit area was plotted as a function of square root of time, in which the initial slope of this curve is defined as the sorptivity coefficient. In addition, for Series B, four different type of liquid was used as the absorbing solution: de-ionized water, 0.5 $\mathrm{M}, 1.0 \mathrm{M}$, and $4.0 \mathrm{M} \mathrm{NaCl}$ solutions. The detailed procedure can also be found in ASTM C1585.

\subsection{Electronic method}

For Series B, besides using gravimetric approach, the electronic method was also used for capillary absorption test. As shown in Figure 1, a series of specimens with a dimension of 40 $\mathrm{mm} \times 40 \mathrm{~mm} \times 160 \mathrm{~mm}$ were prepared. Totally eleven layers of mesh-shaped electronic plates with a mesh size of $5 \mathrm{~mm} \times 5$ $\mathrm{mm}$ were embedded longitudinally inside each sample. The size of electronic plate was $3.5 \mathrm{~cm} \times 4.5 \mathrm{~cm}$, and these eleven electronic plates were buried starting from $1 \mathrm{~cm}$ from the exposed surface, with an interval of $1 \mathrm{~cm}$. The samples were cured at curing regime I for 28 days, then dried using the same procedure in Section 2.3 before performing this test. The D.C. power supply was set to be constantly $3 \mathrm{~V}$ during the tests, while the electronic currents and resistivity between each two successive layers of concrete were measured using VC9805A digital multimeter.

In order to quantify the penetration depth of liquid, it is necessary to know the electronic response for saturated concrete. Therefore, the initial reading was performed on concrete after curing (i.e. submerged under water and before drying). This study uses the ratio between the electronic current of concrete during tests and the electronic current of saturated concrete as a factor representing the variation of moisture content. Therefore, as this ratio for certain location at the certain time remains zero, it is believed that this particular point remains dried and the liquid front has not reached there. The depth of penetration at a certain time was determined as the nearest location from exposure whose electronic current ratio just becomes larger than zero. As a result, it was recognized that the accuracy of this experiments was strongly affected by the arrangement of electronic plates across the samples: the shorter distance between successive plates, the higher accuracy seems to be achieved. 


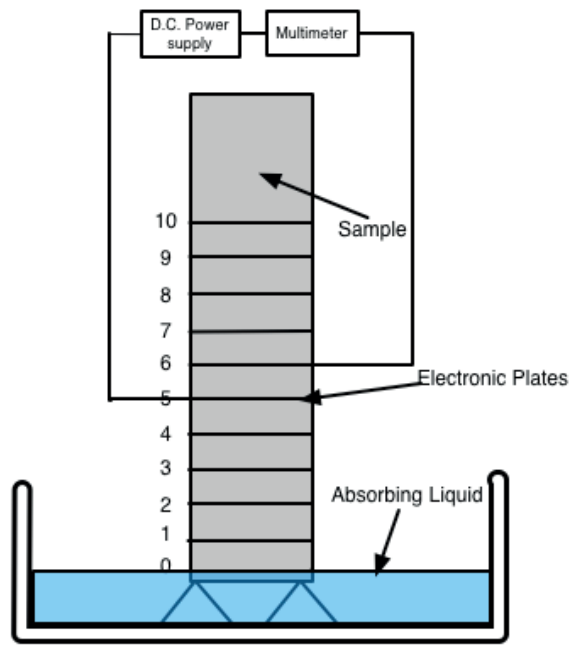

Fig. 1 Experimental set-up for measuring the depth-related variation of the electronic response of concrete during capillary absorption tests (measuring the region between planes 5 and 6 as an example).

\subsection{Mercury Intrusion Porosimetry}

Mercury Intrusion Porosimetry (MIP) was implemented to Series A samples (i.e. OPC, Slag, FA mixtures at 7 and 28 days) after finishing the capillary absorption tests. The MIP was conducted using Micromertics Autopore 9500, which can exert a pressure ranging from $0.005 \sim 600 \mathrm{MPa}$, corresponding a pore entry diameter of 3 358050 $\mathrm{nm}$. Before applying the MIP, all samples were dried using the similar procedure described in Section 2.3.

\section{Results and Discussion}

\subsection{Influence of pore structure}

Figure 2 shows the sorptivity plots for Series A samples cured at various curing regimes for 7 and 28 days. The sorptivity coefficients obtained from Figure 2 are listed in Table 4. It can be seen that when concrete is cured at curing regimes I and II, the incorporation of SCM tends to beneficially reduce the sorptivity coefficient. This positive effect is more obvious when the sample is cured for 28 days. However, when cured at severe curing regime III, the incorporation of SCMs negatively increases the sorptivity coefficient.
In addition, for OPC mixture, curing at the condition I tends to increase the sorptivity over time, while curing at II reduces the sorptivity over time. This difference is likely due to the leaching of OPC concrete when submerging under water, which can negatively affect its absorption properties. For BS mixture, curing at the condition I tends to reduce its sorptivity, while for FA mixture, curing at II is likely to be more beneficial. Nevertheless, the sorptivity property of concrete with SCMs is less sensitive to curing as far as enough moisture (curing regime I and II) is provided. However, its sorptivity property becomes considerably sensitive to drying condition, compared with OPC mixture. All of these findings are likely to imply that the hydration of slag or fly ash (e.g. pozzolanic reaction) demands sufficient supplies of water.

Figures 3, 4 and Table 4 display the pore structure characteristics of Series A samples cured at various conditions for 7 days and 28 days. It can be seen that when cured at condition I or II, the incorporation of SCMs refines the pore structure. Particularly, the proportions of small pores (diameter $<20 \mathrm{~nm}$ ) in BS and FA mixtures are considerably higher than that of OPC mixture. For OPC mixture, most of the pores are in a diameter of 50 110 nm, while for BS and FA mixture, the distribution of pore size is more diverse. However, when cured at condition III, all mixtures tend to have a coarser pore structure. It can be seen that the pore size distribution of BS and FA mixtures tend to become even coarser than OPC when cured at a drying condition.

Figure 5 shows the correlation between sorptivity coefficient and threshold pore diameter and total porosity. It can be seen that there is a reasonable correlation between sorptivity coefficient and threshold pore diameter, while its correlation with porosity is rather poor. This study is likely to imply that the pore size distribution is more important than porosity regarding sorptivity. The larger the threshold pore diameter, the larger sorptivity coefficient tends to be, regardless of SCMs and curing conditions. 


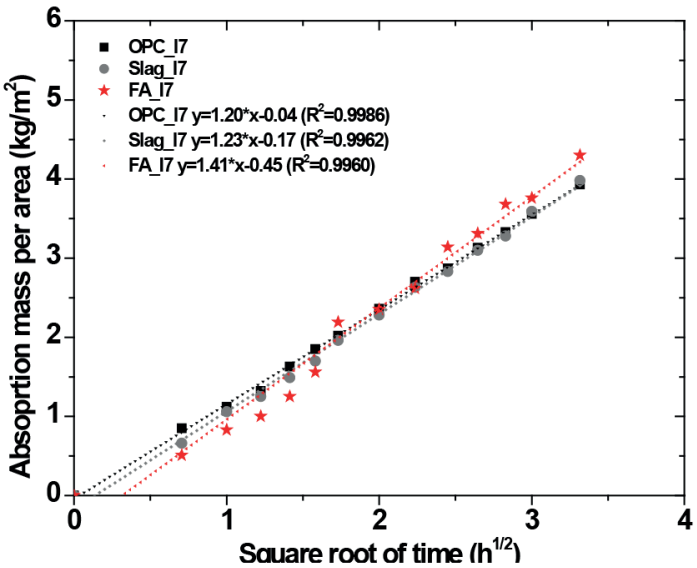

(a)

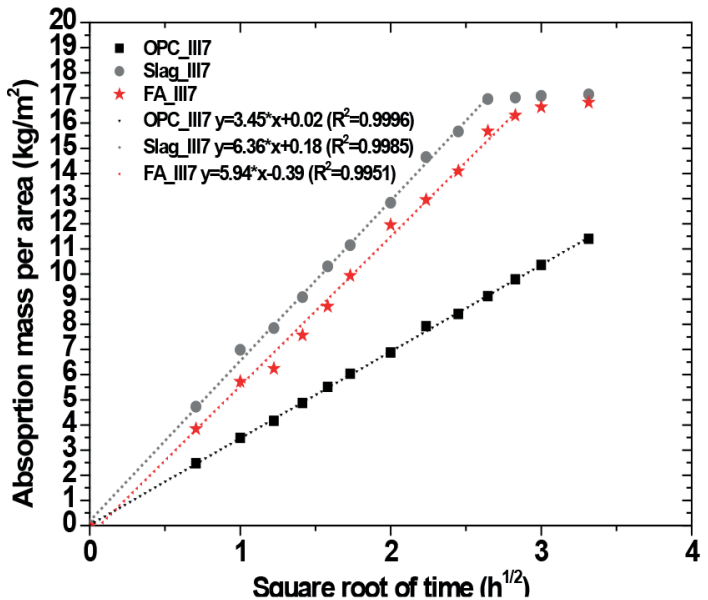

(c)

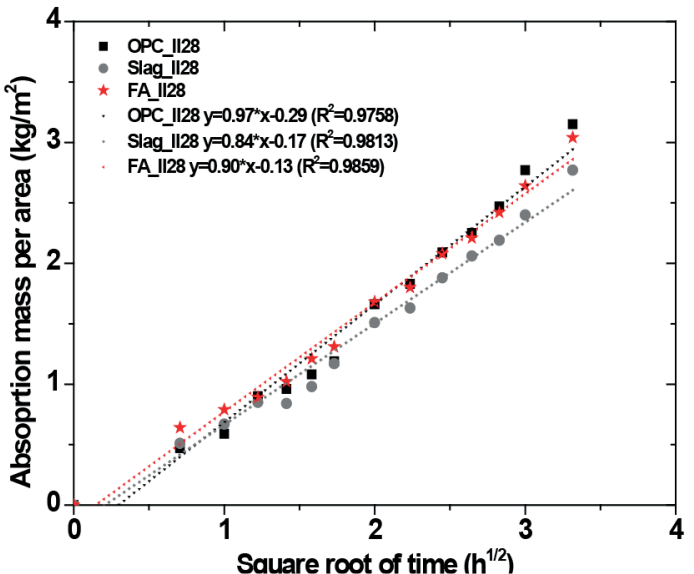

(e)

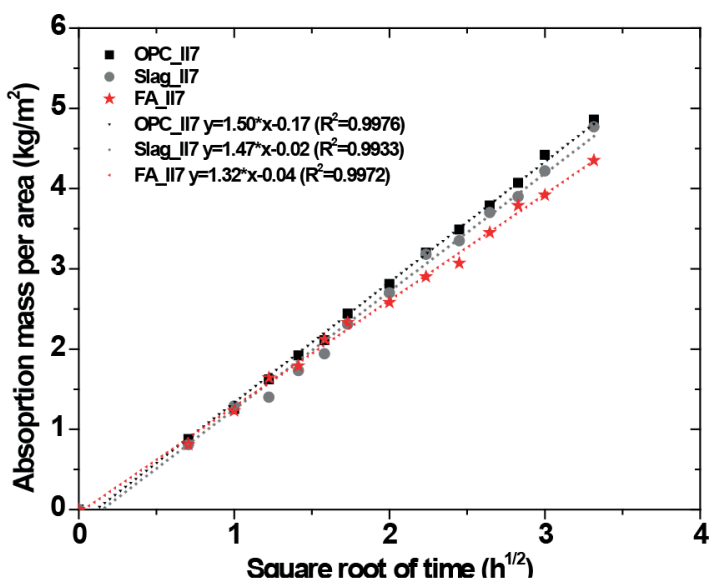

(b)

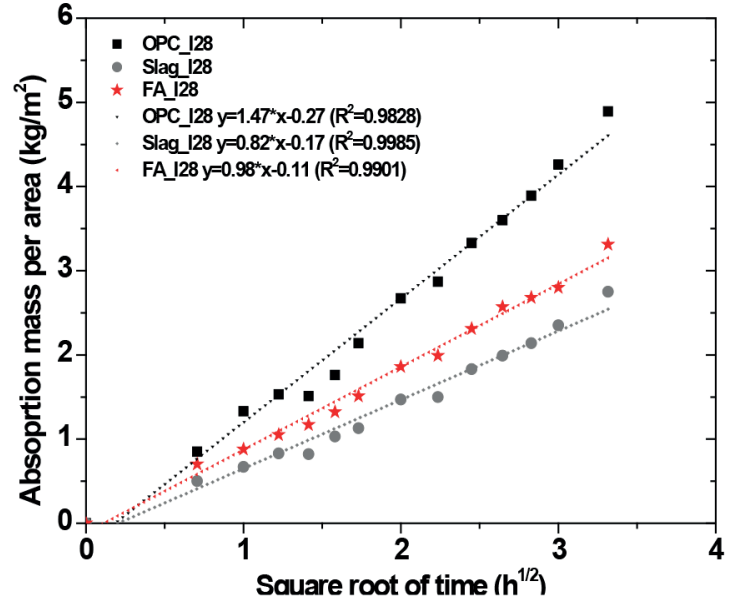

(d)

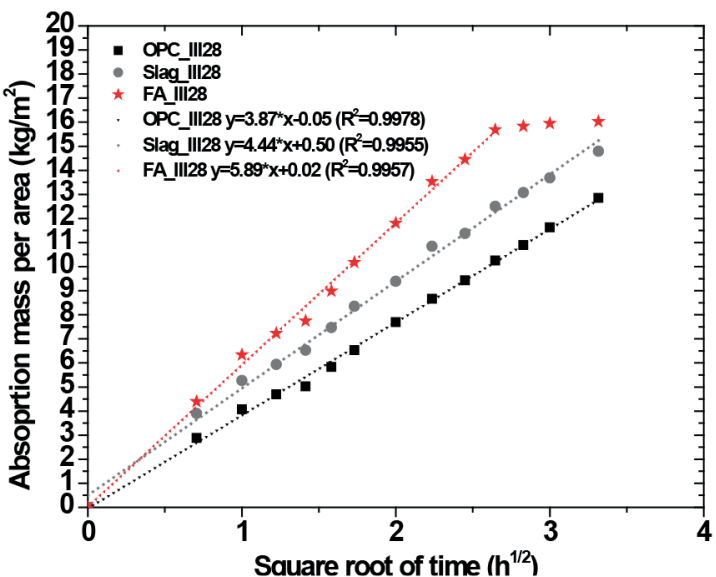

(f)

Fig. 2 Sorptivity plots for Series A samples (a) Cured at curing regime I for 7 days; (b) Cured at curing regime II for 7 days; (c) Cured at curing regime III for 7 days; (d) Cured at curing regime I for 28 days; (e) Cured at curing regime II for 28 days; (f) Cured at curing regime III for 28 days 


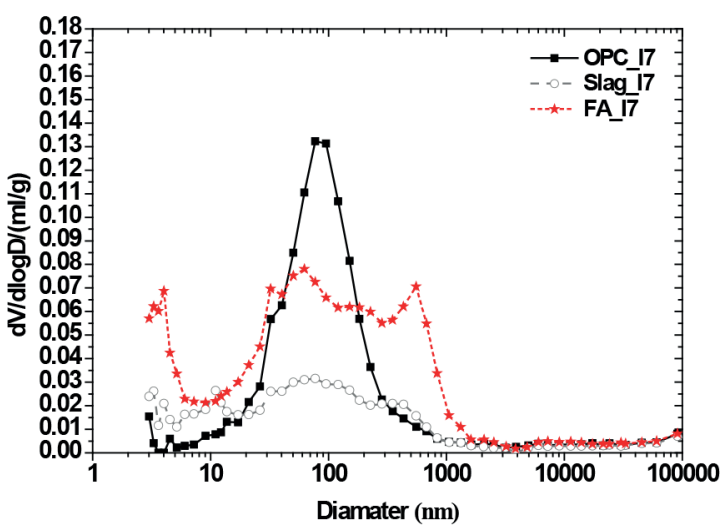

(a)

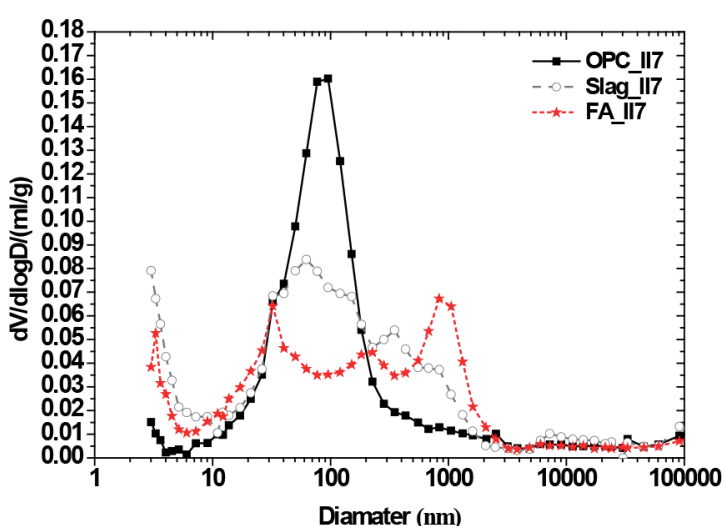

(c)

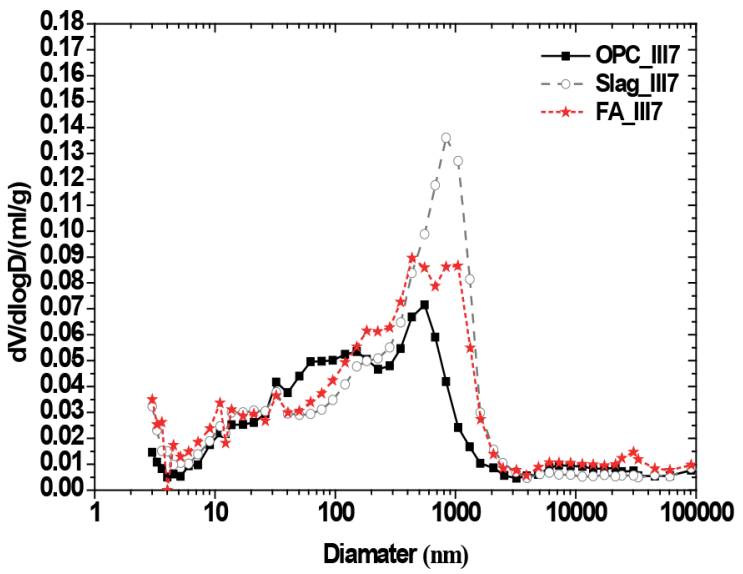

(e)

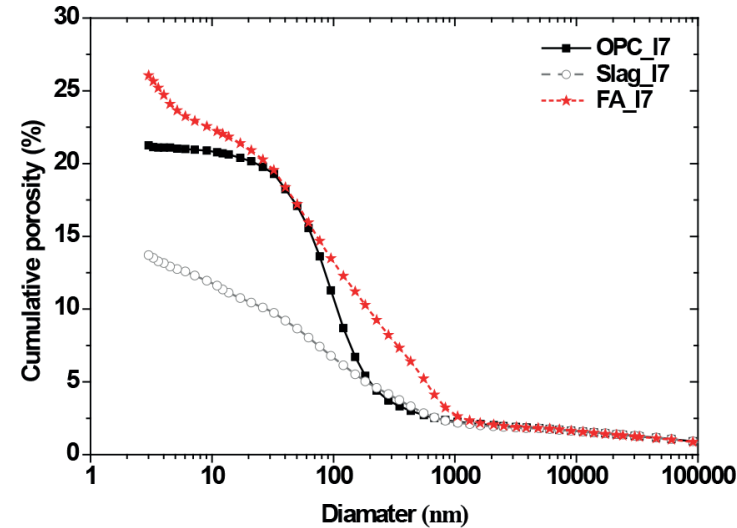

(b)

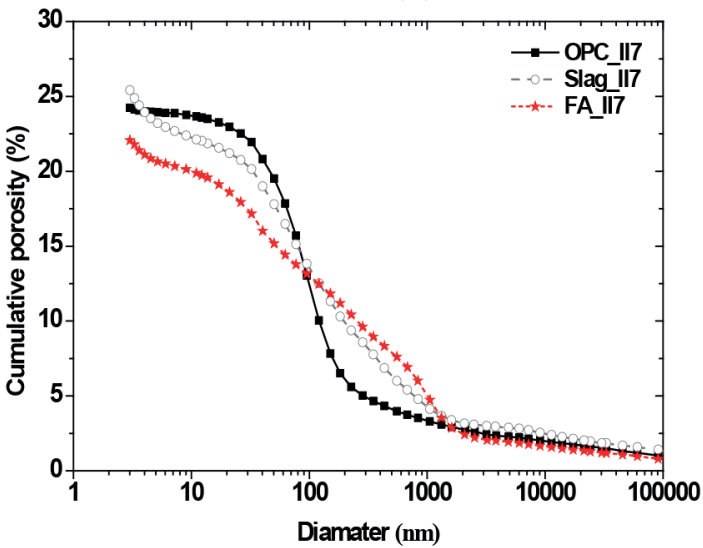

(d)

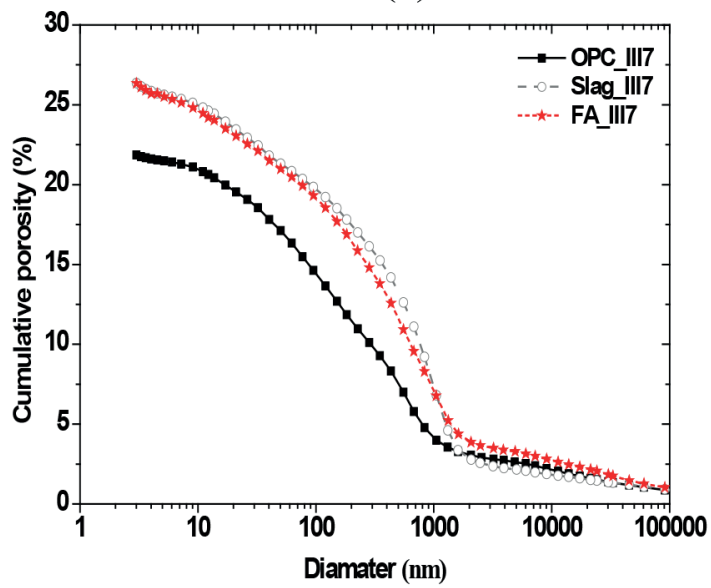

(f)

Fig. 3 The pore structure of Series A samples cured various conditions for 7 days (a) Pore size distribution at curing regime I; (b) Cumulative porosity curves at curing regime I; (c) Pore size distribution at curing regime II; (d) Cumulative porosity curves at curing regime II; (e) Pore size distribution at curing regime III; (f) Cumulative porosity curves at curing regime III 


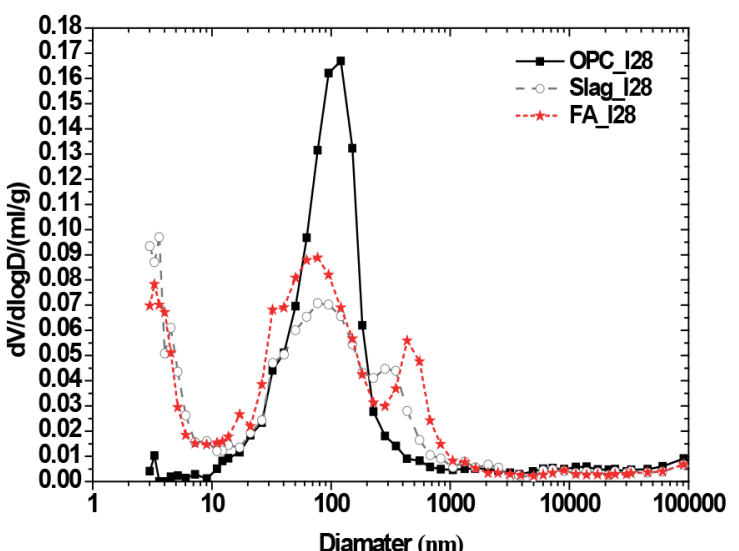

(a)

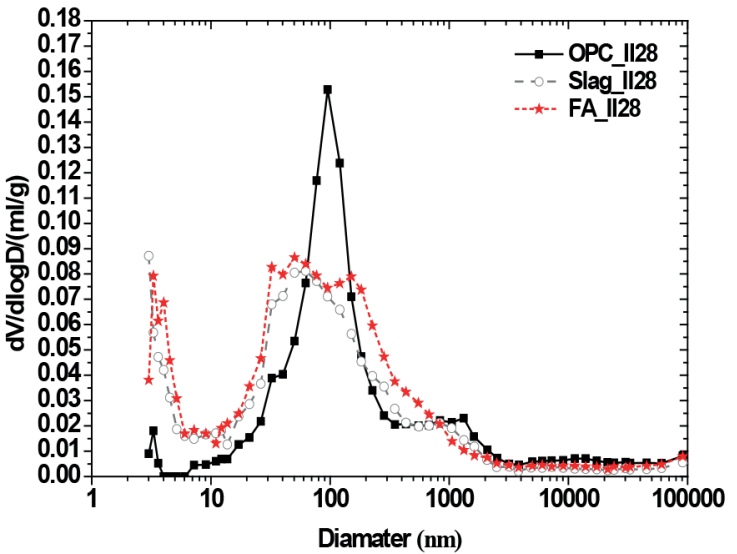

(c)

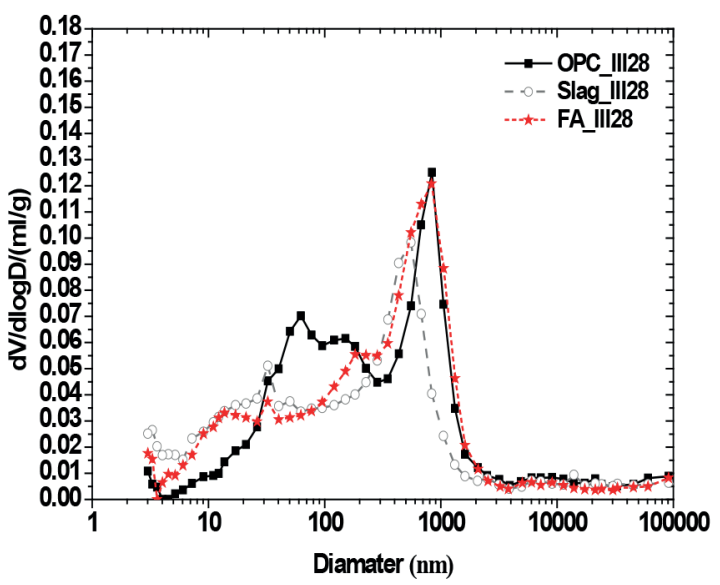

(e)

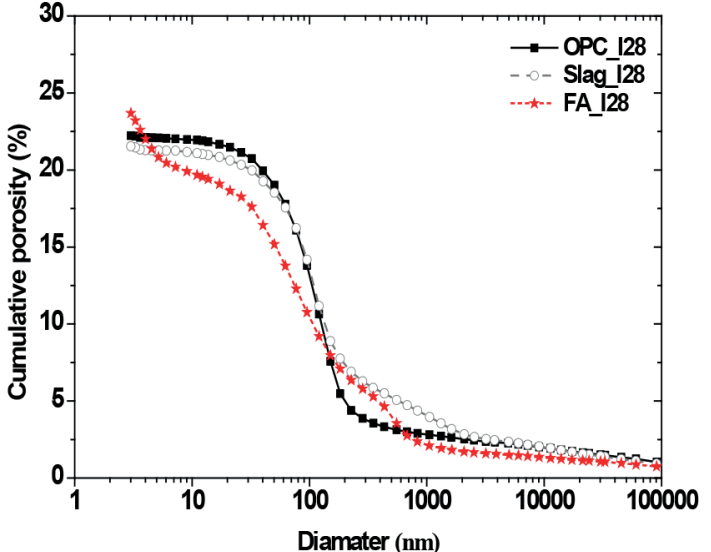

(b)

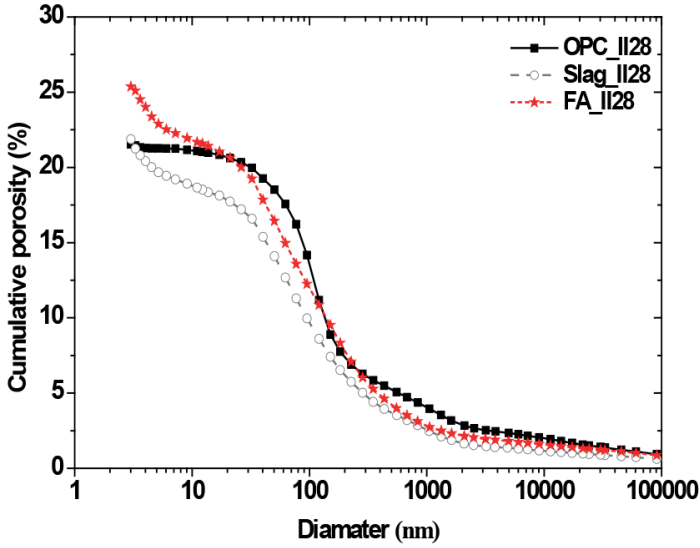

(d)

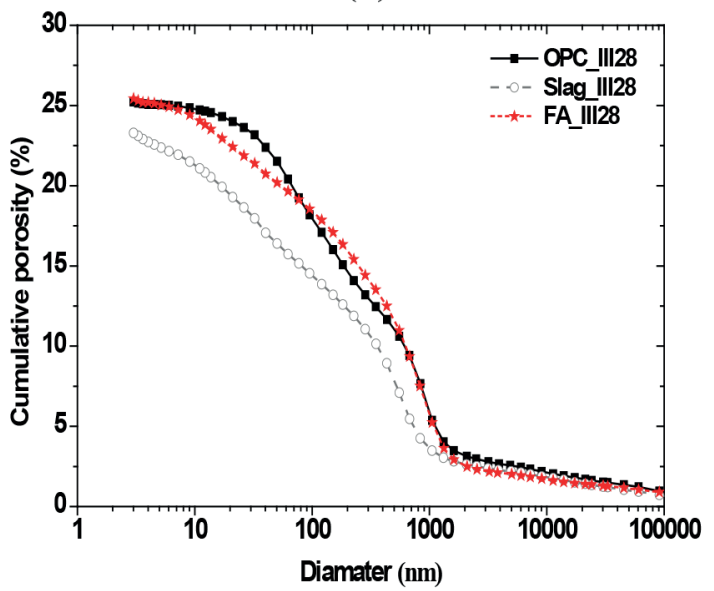

(f)

Fig. 4 The pore structure of Series A samples cured various conditions for 28 days (a) Pore size distribution at curing regime I; (b) Cumulative porosity curves at curing regime I; (c) Pore size distribution at curing regime II; (d) Cumulative porosity curves at curing regime II; (e) Pore size distribution at curing regime III;

(f) Cumulative porosity curves at curing regime III 
Table 4 Pore characteristics and sorptivity coefficient for concrete with SCMs cured at various conditions at two different ages

\begin{tabular}{|c|c|c|c|c|c|c|c|c|c|}
\hline \multirow{2}{*}{ Mixture } & \multirow{2}{*}{ Curing } & \multirow{2}{*}{$\begin{array}{l}\text { Average } \\
(\mathrm{nm})\end{array}$} & \multirow{2}{*}{$\begin{array}{c}\text { Threshold } \\
\text { diameter } \\
(\mathrm{nm})\end{array}$} & \multirow{2}{*}{$\begin{array}{l}\text { Porosity } \\
(\%)\end{array}$} & \multicolumn{4}{|c|}{ Pore size distribution (\%) } & \multirow{2}{*}{$\begin{array}{c}\text { Sorptivity coefficient } \\
{\left[\mathrm{kg} /\left(\mathrm{m}^{2} \cdot \mathrm{h}^{1 / 2}\right)\right]}\end{array}$} \\
\hline & & & & & $<21 \mathrm{~nm}$ & $21 \sim 50 \mathrm{~nm}$ & $50 \sim 227 \mathrm{~nm}$ & $>227 \mathrm{~nm}$ & \\
\hline \multirow{3}{*}{ OPC-7 } & I & 59.5 & 77.1 & 21.25 & 1.09 & 3.07 & 12.69 & 4.4 & 1.1967 \\
\hline & II & 58.5 & 95.4 & 24.23 & 1.26 & 3.46 & 13.92 & 5.59 & 1.5003 \\
\hline & III & 52.1 & 552.8 & 21.86 & 2.33 & 2.41 & 6.16 & 10.96 & 3.4487 \\
\hline \multirow{3}{*}{ BS-7 } & I & 23.5 & 77.1 & 13.71 & 3.27 & 1.78 & 4.08 & 4.58 & 1.2314 \\
\hline & II & 25.4 & 62.5 & 25.41 & 4.2 & 3.41 & 8.43 & 9.37 & 1.4698 \\
\hline & III & 50.5 & 834.8 & 26.36 & 2.91 & 2.14 & 4.31 & 17 & 6.3652 \\
\hline \multirow{3}{*}{ FA-7 } & I & 23.4 & 62.5 & 26.05 & 5.14 & 3.7 & 7.96 & 9.25 & 1.4060 \\
\hline & II & 30.3 & 32.4 & 22.06 & 3.46 & 3.43 & 4.75 & 10.42 & 1.3236 \\
\hline & III & 45.0 & 434.4 & 26.33 & 3.28 & 2.05 & 5.13 & 15.87 & 5.9363 \\
\hline \multirow{3}{*}{ OPC-28 } & I & 72.7 & 120.9 & 22.22 & 0.76 & 2.46 & 14.62 & 4.38 & 1.4707 \\
\hline & II & 69.6 & 95.4 & 21.52 & 0.9 & 2.11 & 11.61 & 6.9 & 0.9744 \\
\hline & III & 83.0 & 836.5 & 25.22 & 1.22 & 2.49 & 7.43 & 14.08 & 3.8673 \\
\hline \multirow{3}{*}{ BS-28 } & I & 16.4 & 77.2 & 21.59 & 5.58 & 2.54 & 7.67 & 5.8 & 0.8166 \\
\hline & II & 22.0 & 62.5 & 21.86 & 4.14 & 3.63 & 8.35 & 5.74 & 0.8376 \\
\hline & III & 34.3 & 554.4 & 23.29 & 4 & 2.9 & 4.51 & 11.88 & 4.4429 \\
\hline \multirow{3}{*}{ FA-28 } & I & 20.1 & 77.1 & 23.68 & 4.04 & 3.47 & 8.83 & 6.34 & 0.9838 \\
\hline & II & 23.0 & 50.4 & 25.37 & 4.74 & 4.2 & 9.35 & 7.08 & 0.9023 \\
\hline & III & 53.5 & 832.2 & 25.43 & 3.02 & 2.22 & 4.79 & 15.4 & 5.8915 \\
\hline
\end{tabular}
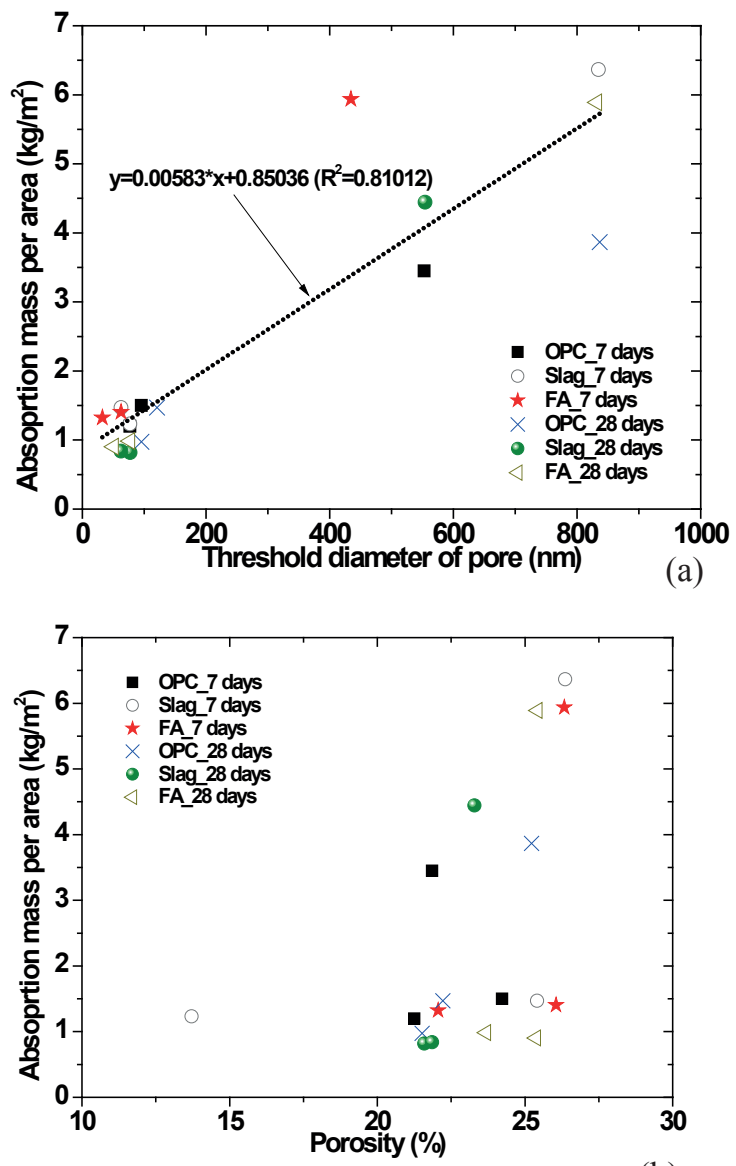

(b)

Fig. 5 Correlation between (a) sorptivity coefficient and threshold pore diameter; (b) sorptivity coefficient and porosity.

\subsection{Influence of liquid properties}

Figures 6,7 show the sorptivity plots and sorptivity coefficients for Series B samples with four different absorbing liquids at various ages using the gravimetric approach. It can be seen that the sorptivity coefficient decreases as the curing time increases, regardless of liquid properties. However, at the same age, it is found that the sorptivity coefficient initially increases as the concentration of $\mathrm{NaCl}$ increases, but then decreases. Considering that the concentration of $\mathrm{NaCl}$ in seawater is about $3.5 \%$ (approximately $0.6162 \mathrm{M}$ ), it is likely to indicate that previous studies using pure water underestimate the sorptivity coefficient of seawater. The reduction of sorptivity coefficient at high concentration is probably due to a considerable change of viscosity and surface tension. However, it should be noted that the gravimetric approach cannot distinguish the different weight of the solution (pure water) and solute $(\mathrm{NaCl})$.

Figure 8 shows the evolution of electronic current ratios in concrete at various locations and time during capillary absorption measurement. It is reasonable to see that the current ratio overall increases as the concentration of $\mathrm{NaCl}$ increases, which basically enlarges the conductivity of concrete. For a certain type of liquid at a certain time, it can be seen that the current ratio gradually decreases down to zero as the exposed depth increases. It indicates that the liquid penetration results in a re-wetting of the surface layer while the interior remains dry. For a certain type of liquid at a certain depth, the current ratio is initially zero, then gradually enlarges as the exposed time increases, then becomes stable fluctuating around a certain value. It indicates the process of concrete from dried to re-wetting then almost saturated. 
Figure 9 shows the correlation between depth of penetration and the square root of time. Similar to the gravimetric method, the depth of penetration and the square root of time for concrete are also in a linear relationship. Contrast by the gravimetric method, the electronic method indicates that $\mathrm{NaCl}$ delays the penetration of liquid into concrete compared with pure water. The primary reason is probably due to the chemical and physical binding of chloride ions onto the hydrated products of concrete (e.g. calcium-silicate-hydrate or AFm phases) [6]. The chloride binding effect is likely to drag the overall movement of liquid, and this influence magnifies as the concentration increases. The findings would emphasize the importance of chloride binding capability of concrete, which if not probably characterized, can overestimate the risk of chloride attack under wetting-drying cycles.
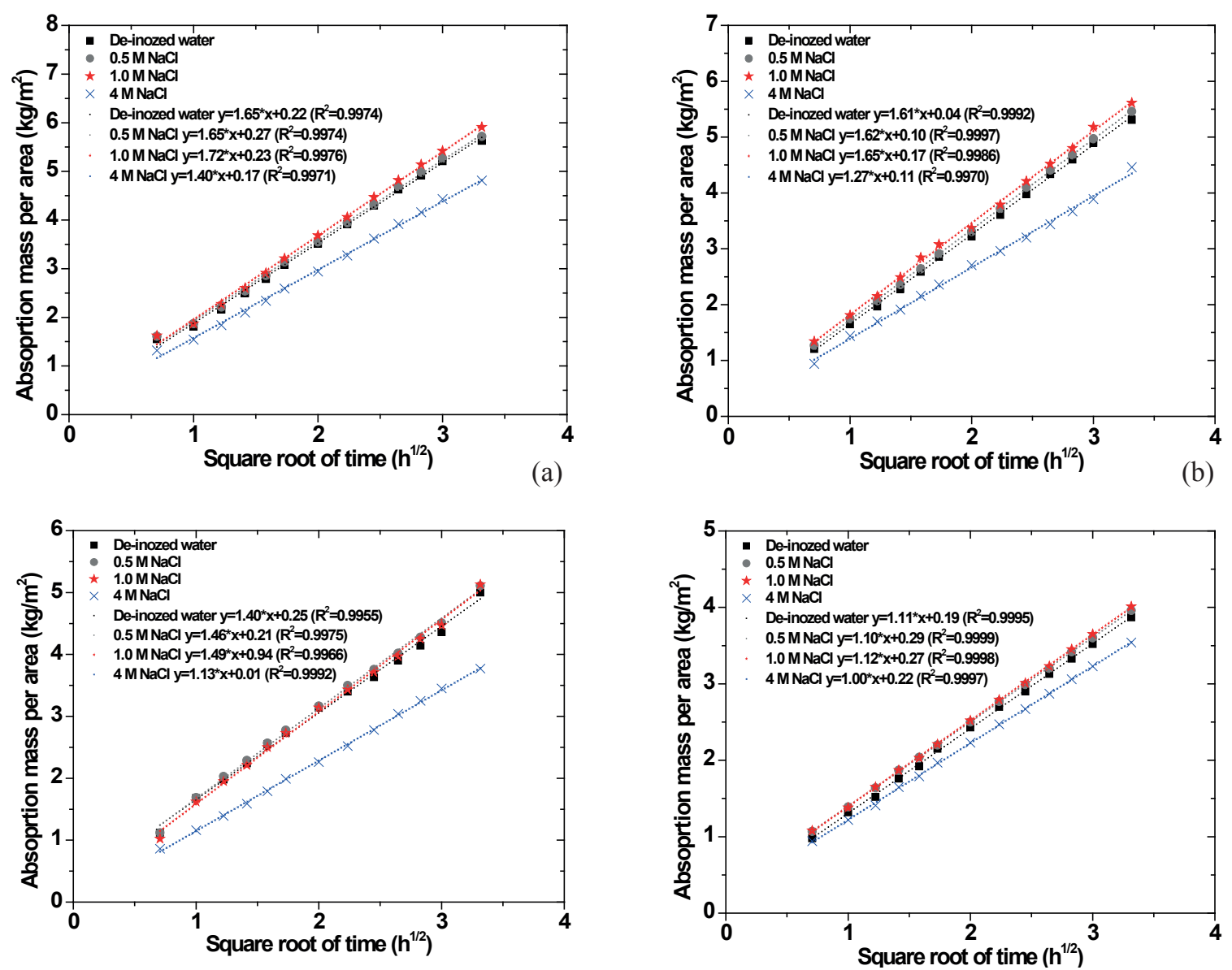

Fig. 6 Sorptivity plots for Series B samples with four different absorbing liquids (a) cured for 1 day; (b) cured for 3 days; (c) cured for 7 days; (d) cured for 28 days

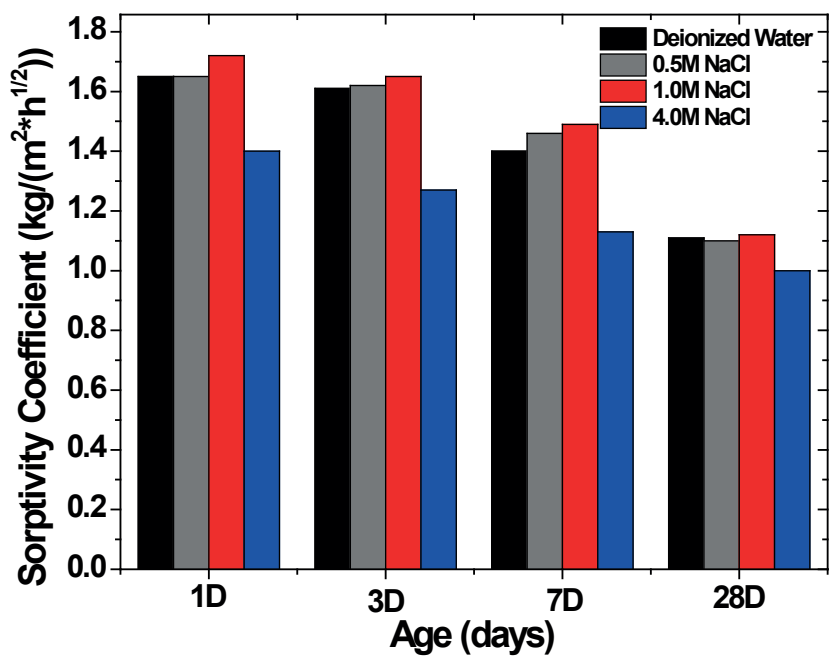

Fig. 7 Evolution of sorptivity coefficient for concrete with four different types of liquids over time 

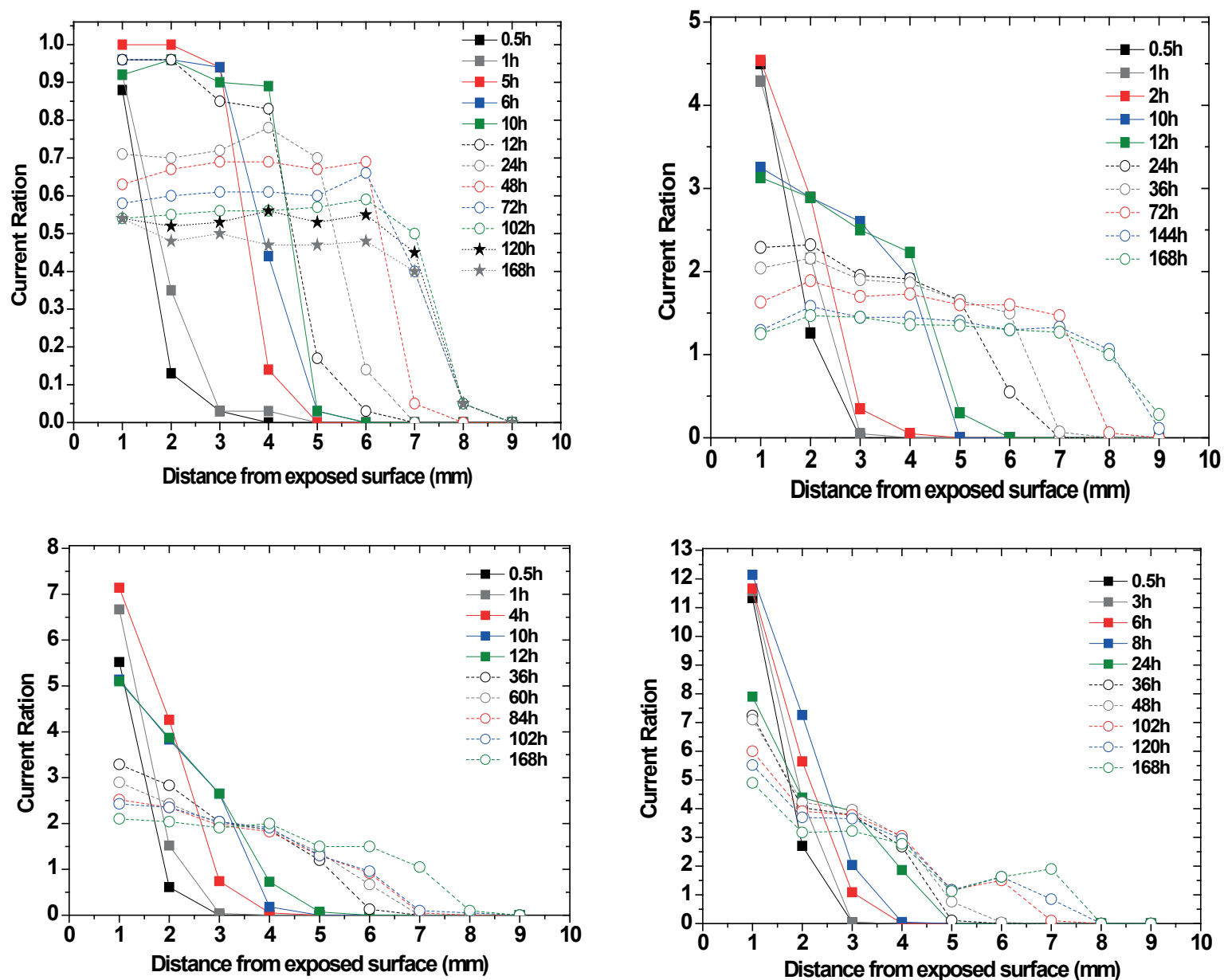

Fig. 8 Evolution of current ration in concrete at various location and time during capillary absorption measurement (a) de-ionized water; (b) $0.5 \mathrm{M}$ NaCl solution; (c) $1.0 \mathrm{M} \mathrm{NaCl}$ solution; (d) $4.0 \mathrm{M} \mathrm{NaCl}$ solution.

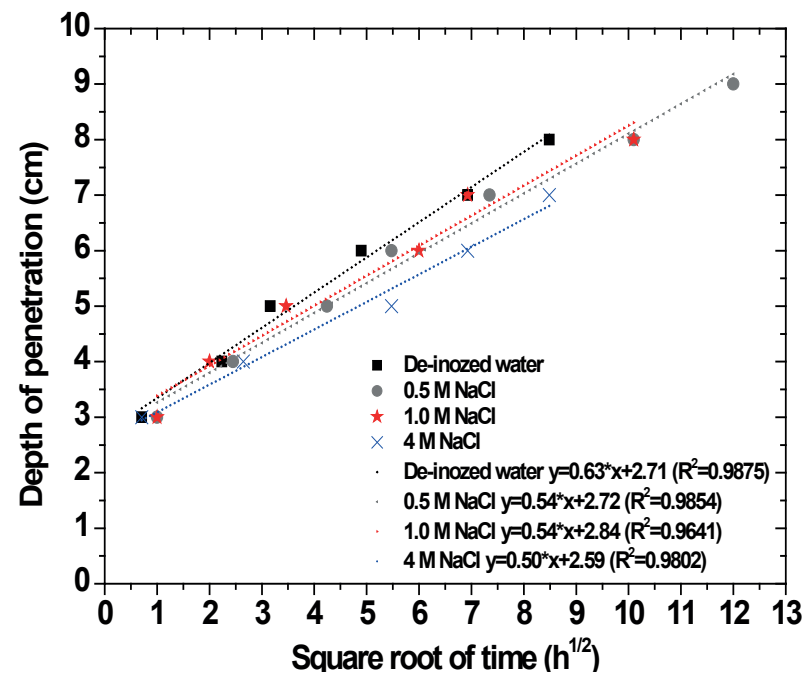

Fig. 9 Correlation between depth of penetration and square root of time 


\section{Conclusions}

In this paper, the effects of SCMs, curing condition, and concentration of $\mathrm{NaCl}$ on the absorption behaviors of concrete were experimentally studied. Following conclusions can be drawn based on this study:

1. The incorporation of SCMs can beneficially reduce the sorptivity when concrete is cured at a condition in which sufficient moisture is provided; otherwise, it exacerbates the sorptivity.

2. Submersion under water for OPC mixture can negatively affect its absorption properties probably due to leaching.

3. The sorptivity coefficient is strongly correlated with the threshold pore size, regardless of the incorporation of SCMs and curing conditions.

4. The ASTM C1585 shows the sorptivity increases when $\mathrm{NaCl}$ concentration first increases up to a certain concentration, then decreases.

5. The electronic method shows that sorptivity consistently decreases as $\mathrm{NaCl}$ concentration increases.

6. The ASTM C1585 cannot differentiate the weights of solute and solution, which may give misleading results when investigating the sorptivity properties of various liquids.

7. The presence of chloride is likely to drag the overall movement of liquid due to chloride binding effects.

\section{Acknowledgements}

The financial support from the National Basic Research Program (Grant No. 2015CB655103), of the People's Republic of China and the National Natural Science Foundation (Grant Nos. 51578497,51320105013 and 51478419 ) is gratefully acknowledged.

\section{References}

[1] Costa, A., Appleton, J. „Chloride penetration into concrete in marine environment-Part I: Main parameters affecting chloride penetration.” Materials and Structures. 32 (4), pp. 252-259. 1999. DOI: 10.1007/ BF02479594

[2] Neville, A. "Chloride attack of reinforced concrete: an overview." Materials and Structures. 28 (2), pp. 63-70. 1995. DOI: 10.1007/ BF02473172

[3] Vu, K. A. T., Stewart, M. G. "Structural reliability of concrete bridges including improved chloride-induced corrosion models." Structural Safety. 22 (4), pp. 313-333. 2000. DOI: 10.1016/S0167-4730(00)00018-7

[4] Song, H. W., Lee, C. H., Ann, K. Y. "Factors influencing chloride transport in concrete structures exposed to marine environments." Cement and Concrete Composites. 30 (2), pp. 113-121. 2008. DOI: 10.1016/j.cemconcomp.2007.09.005

[5] Ye, H., Tian, Y., Jin, N., Jin, X. , Fu, C. "Influence of cracking on chloride diffusivity and moisture influential depth in concrete subjected to simulated environmental conditions." Construction and Building Materials. 47, pp. 66-79. 2013. DOI: 10.1016/j.conbuildmat.2013.04.024

[6] Ye, H., Jin, X., Chen, W., Fu, C., Jin, N. "Prediction of chloride binding isotherms for blended cements." Computers and concrete. 17 (5), pp. 655 672. 2016. DOI: 10.12989/cac.2016.17.5.655
[7] Ye, H., Jin, N., Jin, X., Fu, C. "Model of chloride penetration into cracked concrete subject to drying-wetting cycles." Construction and Building Materials. 36, pp. 259-269. 2012. DOI: 10.1016/j.conbuildmat.2012.05.027

[8] Ye, H., Fu, C., Jin, N., Jin, X. "Influence of flexural loading on chloride ingress in concrete subjected to cyclic drying-wetting condition." Computers and Concrete. 15 (2), pp. 183-198. 2015. DOI: 10.12989/ cac.2015.15.2.183

[9] Ye, H., Jin, X., Fu, C., Jin, N., Xu, Y., Huang, T. “Chloride penetration in concrete exposed to cyclic drying-wetting and carbonation." Construction and Building Materials. 112, pp. 457-463. 2016. DOI: 10.1016/j.conbuildmat.2016.02.194

[10] Ye, H., Jin, N., Jin, X., Fu, C., Chen, W. "Chloride ingress profiles and binding capacity of mortar in cyclic drying-wetting salt fog environments." Construction and Building Materials. 127, pp. 733-742. 2016. DOI: 10.1016/j.conbuildmat.2016.10.059

[11] Kelham, S. "A water absorption test for concrete.” Magazine of Concrete Research. 40 (143), pp. 106-110. 1988. DOI: 10.1680/macr.1988.40.143.106

[12] McCarter, W., Ezirim, H., Emerson, M. "Absorption of water and chloride into concrete.” Magazine of Concrete Research. 44 (158), pp. 31-37. 1992. DOI: $10.1680 /$ macr.1992.44.158.31

[13] Hall, C. "Water sorptivity of mortars and concretes: a review." Magazine of concrete research. 41 (147), pp. 51-61. 1989. DOI: 10.1680/ macr.1989.41.147.51

[14] Castro, J., Bentz, D., Weiss, J. "Effect of sample conditioning on the water absorption of concrete." Cement and Concrete Composites. 33 (8), pp. 805-813. 2011. DOI: 10.1016/j.cemconcomp.2011.05.007

[15] Khatib, J. M. "Effect of initial curing on absorption and pore size distribution of paste and concrete containing slag." KSCE Journal of Civil Engineering. 18 (1), pp. 264-272. 2014. DOI: 10.1007/s12205-014-0449-7

[16] Gopalan, M. K. "Sorptivity of fly ash concretes." Cement and Concrete Research. 26 (8), pp. 1189-1197. 1996. DOI: 10.1016/0008-8846(96)00105-6

[17] Kolias, S., Georgiou, C. "The effect of paste volume and of water content on the strength and water absorption of concrete." Cement and Concrete Composites. 27 (2), pp. 211-216. 2005. DOI: 10.1016/j. cemconcomp.2004.02.009

[18] Liu, J., Xing, F., Dong, B., Ma, H., Pan, D. "Study on water sorptivity of the surface layer of concrete." Materials and structures. 47 (11), pp. 19411951. 2014. DOI: 10.1617/s11527-013-0162-X

[19] Macinnis, C., Nathawad, Y. "The effects of a deicing agent on the absorption and permeability of various concretes." ASTM special technical publication (691), pp. 485-496. 1980. DOI: 10.1520/STP36083S

[20] Hall, C., Hoff, W. D. "Water transport in brick, stone and concrete." 374 p. CRC Press, Boca Raton. 2011. URL 